\title{
Clinical and biomechanical results of multilevel orthopaedic interventions in crouch-gait patients
}

\author{
T.I. Dolganova, O.I. Gatamov, G.M. Chibirov, D.V. Dolganov, D.A. Popkov
}

Ilizarov National Medical Research Centre for Traumatology and Orthopedics, Kurgan, Russian Federation

\begin{abstract}
The aim of this study was to evaluate the results of multilevel interventions in patients with spastic diplegia and crouch gait. Materials and methods The study cohort consisted of 39 patients (10 females, 29 males). The average age of the patients was $16.3 \pm 4.29$ years (range, 7 to 26 years). In 19 cases, the GMFCS level was III, in 16 cases it corresponded to level II and in 4 cases to level I. The gait study data were analyzed in two groups of patients. In group 1, patients did not have any previous orthopedic interventions, and the crouch gait pattern was considered to have developed naturally (15 patients). In group 2, patients underwent previous operations on the tendon-muscular apparatus (in other medical institutions) such as fibromyotomy (16 patients) or open lengthening of the Achilles tendon (8 patients). The crouch gait pattern in group 2 was considered iatrogenic. Gait analysis using the Edinburgh Scale and 3D analysis was performed before surgery, and at one to 2 years after the interventions. Results Upon comparing the pre- and postoperative indicators of the Edinburgh scale, there was an improvement in the indicators of movements in the ankle joint both in the supporting and in the non-supporting phases of the stride cycle for both groups: a decrease in the maximum dorsal flexion of the foot under load, an improvement in the maximum extension in the knee joint during the support phase, practically complete elimination of the pathological orientation of the foot relative to the motion vector, as well as improvement of the position in the knee joint immediately before the initial contact with the supporting surface. Computer gait analysis showed that multilevel surgical interventions improved the parameters of the knee flexion angle at the time of initial contact, increased the amplitude of knee joint extension in the support phase of the stride, normalized the orientation of the foot relative to the motion vector, reduced or completely corrected the pathological values of the dorsal flexion of the foot in the support phase of the stride and reduced the energetic intensity of movements. There was no significant increase in the indicators reflecting the strength characteristics of the plantar flexors, which reflects a pronounced suppression of the function of these muscles in the development of crouch gait. GPS changed from 17.1 \pm 3.01 to $13.4 \pm 3.19$ for natural crouch gait and from $15.9 \pm 6.16$ to $14.8 \pm 4.6$ for iatrogenic one. Conclusion The crouch gait pattern is not homogeneous, both in terms of natural and iatrogenic development, and in terms of orthopedic disorders. The iatrogenic pattern develops with excessive surgical weakening of the plantar flexors of the foot, even if there is no pathological rotation of the lower limb segments in younger patients and with lower GMFCS levels. The planning of multilevel surgical treatment is based on 3D gait analysis and should be aimed at eliminating orthopedic components of the pathology that determine the crouch gait pattern. Surgical treatment enables to improve the kinetics and kinematics in the knee joint and the kinematic indicators of the ankle joint and, in general, increase the gait profile indicator.
\end{abstract}

Keywords: cerebral palsy, single-event multilevel orthopedic surgery, crouch gait

\section{INTRODUCTION}

Cerebral palsy is one of the most frequent causes of movement deviations [1, 2]. One of them, the crouch gait pathological pattern (gait with permanent knee joint flexion and foot dorsiflexion) prevails in older children, adolescents, and adults with the level of global motor functions GMFCS I-III [3-7]. This gait disorder stands out as a separate pattern IV in the classic work of Rodda JM et al. [8]. This pattern is characterized by flexion of the knee joint more than $15^{\circ}$ at the moment of initial contact of the support phase (stance) of the stride [4, 8-10], as well as permanent dorsiflexion of the foot, flexion of the hip, which is often combined with intratorsional deformity of the femur (excessive anteversion of the femoral neck), external rotational position of the foot relative to the patient's motion vector caused by its severe planovalgus deformity with extremely pronounced abduction of the anterior foot and/or external torsional deformity of the lower leg bones [11-13].

This pattern of pathological gait in spastic diplegia is considered as the final stage in the evolution of gait disorders observed in older children and adults [8]. In the natural course of events, after this type of gait has developed, its constituent components aggravate: an increase in foot deformity in the middle and hind part and an increase in the degree of foot dorsiflexion in the supporting phase, as well as flexion contractures of the knee and hip joints [1417]. This degradation is facilitated by the progressive high position of the patella (patella alta) and torsional deformities of the limb segments, which are the cause of the dysfunction of the levers that reduce the amount of forces generated by the muscle contraction $[9,18,19]$. The negative phenomena of crouch gait progression are the development of pain associated with arthrosis of the joints of the foot, early femoro-patellar arthrosis, apophysitis of the lower pole of the patella, a gradual decrease in the ability to move independently up to a complete loss of the ability to walk independently, even with assistive devices [2, 11, 20, 21].

Currently, the standard surgical orthopedic treatment of crouch gait is simultaneous multilevel orthopedic interventions that provide correction of primary and secondary orthopedic disorders due to this gait pattern [5, 22-25]. This approach eliminates the outdated method of frequent, even annual, separate interventions [20, 26, 27]. Simultaneous multilevel interventions significantly reduce the total number of operations, reduce the time of postoperative recovery and rehabilitation, and have economic advantages [8, 15, 27, 28]. However, the planning of such an

Dolganova T.I., Gatamov O.I., Chibirov G.M., Dolganov D.V., Popkov D.A. Clinical and biomechanical results of multilevel orthopaedic interventions in crouch-gait patients. Genij Ortopedii, 2020, vol. 26, no 3, pp. 325-333. DOI 10.18019/1028-4427-2020-26-3-325-333 
approach requires a 3D Gait Analysis and comparison of its results with clinical and radiological studies [23, 29].

Patients with crouch gait are not a homogeneous group. Their individual orthopedic elements requiring surgical correction may vary $[5,8,22,30,31]$. There is also a naturally developed pattern of crouch gait, which is usually observed during puberty and is associated with an increase in body weight and muscle weakness, and iatrogenic crouch gai, caused by lengthening of the Achilles tendon, aponeurotomy of the calf muscles without correction of disorders at the proximal level, and early interventions of the fibromyotomy type on still spastic muscles before the onset of their retraction [10, 22, 32, 33].

The aim of this study was to evaluate the results of multilevel orthopedic interventions in children and adults with spastic diplegia and crouch gait type, as well as to compare the features of natural and iatrogenic crouch gait patterns in the preoperative period and to compare the results of their correction in terms of changes in gait characteristics.

\section{MATERIAL AND METHODS}

The present study included patients with spastic diplegia, capable of independent movement with or without support aids, whose gait pattern was classified as crouch gait. Those patients underwent multilevel single-event orthopedic interventions; observational and computerized gait analysis was performed before surgery, and also after a follow-up period of at least 12 months.

The study did not include patients with spastic diplegia but with other types of gait disturbance, patients with a functioning baclofen pump, cases of botulinum therapy with an interval of less than 6 months before surgery, as well as patients with ataxic, dystonic forms of cerebral palsy, and patients with hereditary spastic paraplegia.

Finally, the study cohort consisted of 39 patients (10 females, 29 males). The average age of the patients was $16.3 \pm 4.29$ years (range, 7 to 26 years).

In the entire sample, 19 cases had the GMFCS level III, 16 cases corresponded to level II and 4 cases to level I according to GMFCS. The level of movement disorders was assessed clinically, as well as according to medical records and anamnestic data.

The gait study data were analyzed in two patients' groups. In group 1, patients had not previously undergone any orthopedic interventions on the lower extremities, and the crouch gait pattern was considered to have developed naturally (15 patients). In group 2 , patients had previous operations on the tendon-muscular apparatus (at other medical institutions according to medical documents), which involved single or multiple fibromyotomy (16 patients), open lengthening of the Achilles tendon (8 patients). The crouch gait pattern in group 2 was considered iatrogenic.

Gait analysis using the Edinburgh scale [32] was performed before surgery, 1-2 years after surgery in all patients. In addition, the patients underwent a computer analysis of gait parameters at the Ilizarov Gait Analysis Laboratory [29].

The study of kinematics and kinetics of patient movements used 6 Oqus cameras of Qualisys and 1 AMTI (Advanced Mechanical Technology Inc., Watertown, MA) platform with passive marker video capture technology. Patients walked barefoot, if necessary supported by the hands, at their usual speed on a 7-meter track. When placing markers, the IOR model was used [21], which is suitable for analyzing a patient's walking at a low speed and reduces artifacts of skin movement.

The AtteStat 12.0.5 software was used for statistical data processing. Descriptive statistics was applied for mean values and standard deviations. To determine the significance of differences and clinical assessment of gait before surgery and in the long-term period within the groups according to the Edinburgh Scale, the Wilcoxon T-test was used for associated samples. To compare the groups with each other according to the quantitative criteria of 3D gait analysis, the Wilcoxon W-test was used for independent samples. Differences were considered significant at $\mathrm{p}$ less than 0.05 . To compare the incidence of the ability to walk without aids (allowing for the combination of cases corresponding to GMFCS levels I and II) and using canes or crutches (GMFCS III) in the groups of natural and iatrogenic crouch gait pattern, the chi-square test was used for binary samples.

\section{RESULTS}

Table 1 shows the distribution of patients by age, gender, and level of global motor functions.

We should note a significant difference between the indicators of age at operation implementation ( $p=0.013$ ), which apparently indicates an earlier development of orthopedic complications characteristic of iatrogenic crouch gait that required surgical correction. Moreover, there is a significant difference between the groups in the chi-square test $(p=0.0301)$ in the incidence of motor function disorders corresponding to GMFCS level III. It indicates a significantly higher probability of the crouch gait pattern development after open lengthening of the Achilles tendon or percutaneous fibromyotomy, even with a more favorable level of disorders of global motor functions (GMFCS I-II) than with the natural evolution of orthopedic disorders.

On average, 10.1 surgical elements per intervention were performed in each patient in both group 1 and group 2 (Table 1), which reflects the multiplicity of interrelated orthopedic problems that arise in older children and young adults by the development of crouch gait.

It should be noted that in the group of iatrogenic pathological gait, shortening of the Achilles tendon and transfer of the tendon of the peroneus longus muscle to the heel bone in order to enhance the function of plantar flexion become necessary elements of the intervention in many cases. Moreover, there were practically no indications for lengthening the triceps of the lower leg. Both features of surgical treatment in group 2 were due to previous surgical interventions.

The average values for each of the indicators of the Edinburgh scale, studied in the pre- and postoperative period, are presented in Table 3. In general, there was an improvement in the kinematic parameters of gait in patients after the operations and in the subsequent period of rehabilitation. 
By comparing pre- and postoperative indicators, we noted a clear improvement in the indicators of movements in the ankle joint both in the support and in the nonsupport phases of the gait cycle in both groups (Fig. 1 and 2): a decrease in the maximum foot dorsiflexion under load, an improvement in the maximum knee joint extension in the support phase, almost complete elimination of the pathological orientation of the foot relative to the motion vector, and improvement of the knee joint position immediately before the initial contact with the supporting surface. Thus, surgical treatment improved the interrelated kinematics in the ankle and knee joints after eliminating joint contractures and leverage dysfunction associated with deformities in the horizontal plane. However, the improvements in movements in the hip joints were not so pronounced. There were practically no improvements in the position of the trunk at different moments of the gait cycle.

Table 1

Distribution of patients by age, gender, and level of global motor functions

\begin{tabular}{|c|c|c|c|c|c|c|}
\hline \multirow{2}{*}{ Group } & \multirow{2}{*}{ Number of patients } & \multirow{2}{*}{ Females/Males } & \multirow{2}{*}{ Age, years } & \multicolumn{3}{|c|}{ GMFCS; number of cases } \\
\cline { 4 - 7 } & & & & I & II & III \\
\hline 1 & 15 & $4 / 11$ & $18.9 \pm 4.75$ & - & 4 & 11 \\
\hline 2 & 24 & $6 / 18$ & $14.8 \pm 3.07$ & 4 & 13 & 7 \\
\hline
\end{tabular}

Elements of surgical interventions, number

Table 2

\begin{tabular}{|c|c|c|}
\hline Element of intervention & Group 1 & Group 2 \\
\hline Lengthening of the medial group of knee flexors & 30 & 48 \\
\hline Lengthening of adductors & 8 & 4 \\
\hline Aponeurotomy of the gastrocnemius muscle, lengthening of the Achilles tendon & 28 & 7 \\
\hline Shortening of $\mathrm{m}$. tibialis posterior tendon & 18 & 28 \\
\hline Supracondylar extension and detorsion osteotomy & 8 & 18 \\
\hline Bringing the patella down & 22 & 42 \\
\hline Detorsion osteotomy of the femur & 6 & 8 \\
\hline Distal transfer of $\mathrm{m}$. rectus femoris & 2 & 8 \\
\hline Lengthening of $\mathrm{m}$. iliopsoas & 4 & - \\
\hline Detorsion osteotomy of the lower leg bones & 2 & 1 \\
\hline Talonavicular arthrodesis & 8 & 8 \\
\hline Foot deformity correction according to Evans & 4 & 12 \\
\hline Triple arthrodesis & 6 & 16 \\
\hline Peroneus longus tendon transfer on to the heel bone & - & 7 \\
\hline Shortening of the Achilles tendon & - & 12 \\
\hline Dissection of retinaculum extensorum/lengthening of the tendon of the anterior tibial muscle & - & 2 \\
\hline Hallux valgus correction, including arthrodesis of first phalangeal joint & 11 & 20 \\
\hline Total & 155 & 241 \\
\hline
\end{tabular}

Mean values of the Edinburgh scale before the operation and after 1-2 years after the intervention

\begin{tabular}{|l|c|c|c|c|}
\hline \multirow{2}{*}{\multicolumn{1}{|c|}{ Parameter }} & \multicolumn{2}{|c|}{ Group 1 } & Group 2 \\
\cline { 2 - 4 } & Before treatment & $1-2$ years after treatment & Before treatment & $1-2$ years after treatment \\
\hline Initial contact & $1.4 \pm 0.50$ & $0.7 \pm 0.52$ & $1.2 \pm 0.51$ & $0.67 \pm 0.50$ \\
\hline Heel lift & $1.3 \pm 0.53$ & $0.9 \pm 0.25$ & $1.02 \pm 0.5$ & $0.75 \pm 0.38$ \\
\hline Maximum ankle dorsiflexion & $1.4 \pm 0.50$ & $0.3 \pm 0.53^{*}$ & $1.5 \pm 0.54$ & $0.21 \pm 0.42^{*}$ \\
\hline Hind-foot varus/valgus & $1.5 \pm 0.68$ & $0.27 \pm 0.45^{*}$ & $1.35 \pm 0.73$ & $0.2 \pm 0.32^{*}$ \\
\hline Foot progression angle & $1.7 \pm 0.58$ & $0.23 \pm 0.50^{*}$ & $1.44 \pm 0.69$ & $0.3 \pm 0.55^{*}$ \\
\hline Knee progression angle & $1.1 \pm 0.63$ & $0.53 \pm 0.51$ & $0.88 \pm 0.69$ & $0.4 \pm 0.48$ \\
\hline Peak knee extension & $1.8 \pm 0.38$ & $0.47 \pm 0.57^{*}$ & $1.7 \pm 0.47$ & $0.27 \pm 0.49^{*}$ \\
\hline Peak hip extension & $1.5 \pm 0.57$ & $0.8 \pm 0.81$ & $1.17 \pm 0.79$ & $0.58 \pm 0.51$ \\
\hline Pelvic obliquity at Mid-Stance & $0.97 \pm 0.41$ & $1.03 \pm 0.32$ & $1.13 \pm 0.74$ & $0.96 \pm 0.48$ \\
\hline Pelvic rotation at Mid-Stance & $0.6 \pm 0.72$ & $0.33 \pm 0.48$ & $0.71 \pm 0.73$ & $0.46 \pm 0.55$ \\
\hline Trunk Peak Sagittal Position & $1.1 \pm 0.48$ & $1.17 \pm 0.83$ & $1.2 \pm 0.68$ & $1.04 \pm 0.67$ \\
\hline Trunk maximum lateral shift & $1.5 \pm 0.51$ & $1.4 \pm 0.5$ & $1.9 \pm 0.23$ & $1.6 \pm 0.54$ \\
\hline Clearance & $1.1 \pm 0.45$ & $0.43 \pm 0.50$ & $0.78 \pm 0.62$ & $0.5 \pm 0.51$ \\
\hline Maximum ankle dorsiflexion & $0.77 \pm 0.68$ & $0.1 \pm 0.31$ & $0.94 \pm 0.87$ & $0.19 \pm 0.40$ \\
\hline Peak knee flexion & $1.2 \pm 0.75$ & $0.7 \pm 0.58$ & $1.1 \pm 0.71$ & $0.63 \pm 0.59$ \\
\hline Knee terminal swing position & $1.7 \pm 0.47$ & $0.47 \pm 0.63^{*}$ & $1.6 \pm 0.49$ & $0.52 \pm 0.50^{*}$ \\
\hline Peak hip flexion & $1.1 \pm 0.78$ & $0.5 \pm 0.51$ & $0.79 \pm 0.88$ & $0.33 \pm 0.48$ \\
\hline Total & $43.7 \pm 7.54$ & $20.9 \pm 8.98^{*}$ & $40.8 \pm 10.91$ & $19.2 \pm 6.05^{*}$ \\
\hline
\end{tabular}

Note: * - significant difference with the initial total indicator according to the paired Wilcoxon test $(\mathrm{p}<0.05)$ 


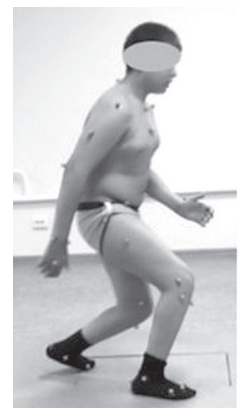

a

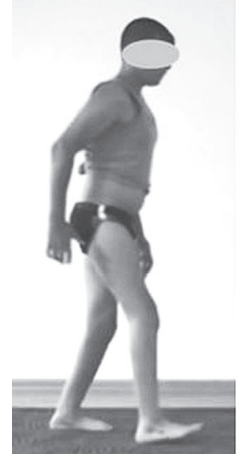

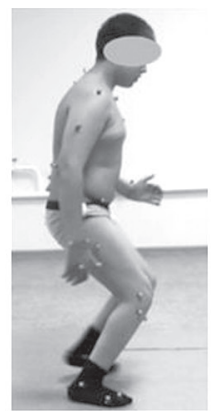

b

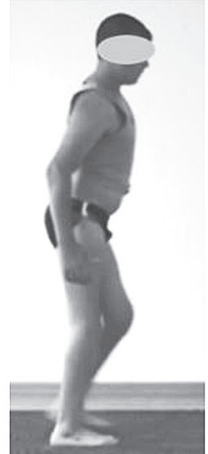

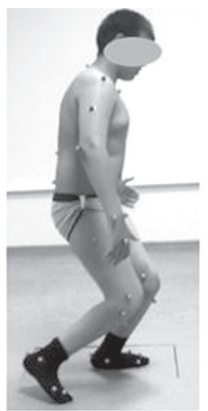

C

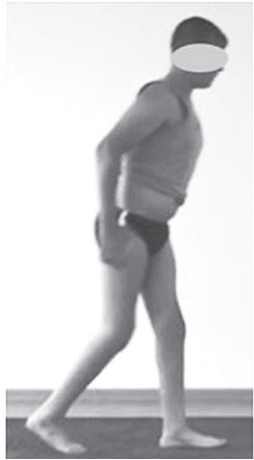

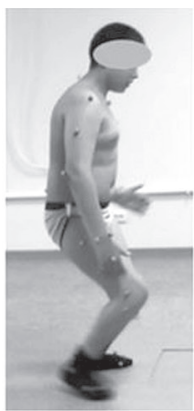

d

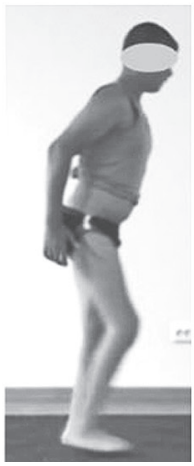

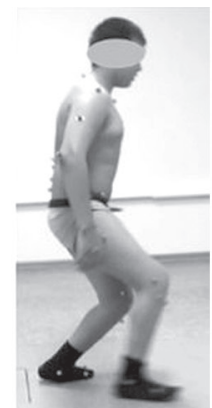

$\mathrm{e}$

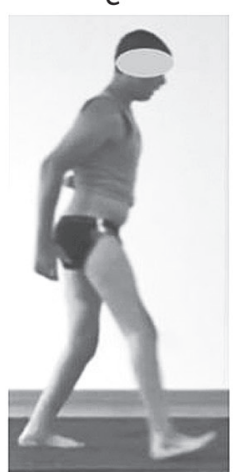

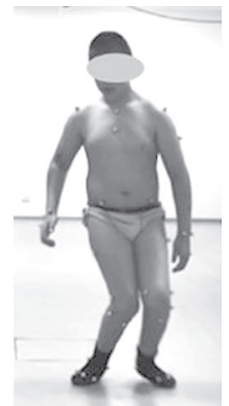
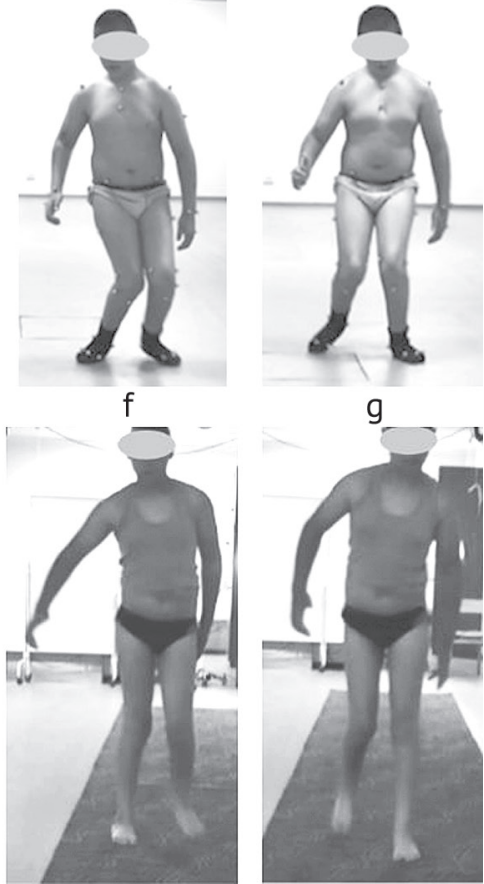

Fig. 1 Gait of patient O., 18 years old, GMFCS II, top row - before treatment, bottom row - 2 years after surgery: $a$ - initial contact (on the whole foot before treatment, on the heel after it); $b$ - middle stance (increased foot dorsiflexion before treatment, pathological excessive flexion in the knee joint; normalization of the kinematic parameters of maximum dorsal flexion of the foot and maximum extension in the knee joint after treatment; $c$ - toe-off, stride length became clearly longer after surgery; $d$ - mid swing, normalization of knee flexion and step clearance after surgery; $e$ - position of the knee joint before the foot contact with the surface, normalization of knee flexion after surgery; $f, g$ - external deviation of the bearing limb foot and normal orientation of the bearing foot after treatment

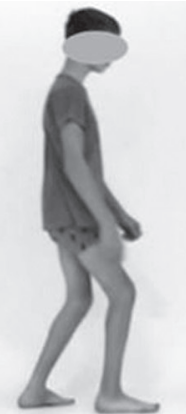

a

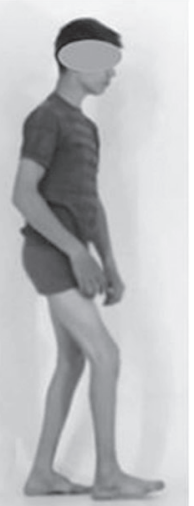

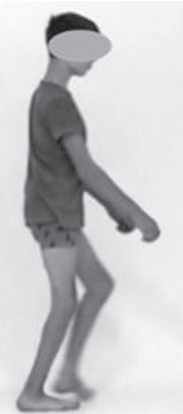

b

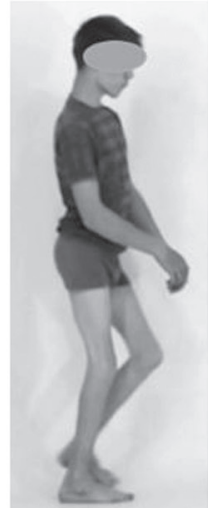

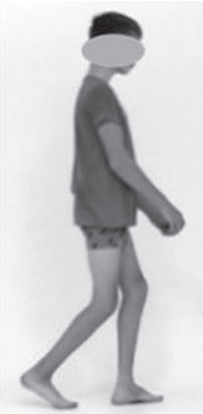

C

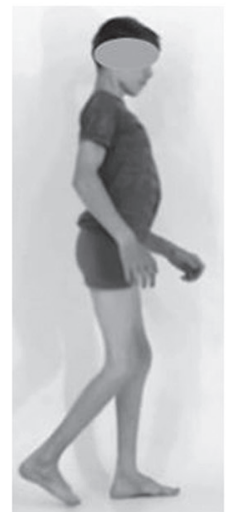

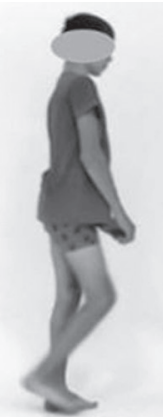

d

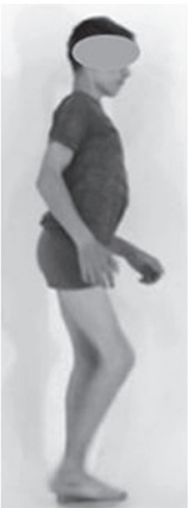

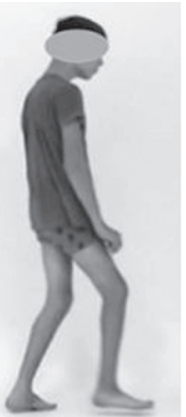

e

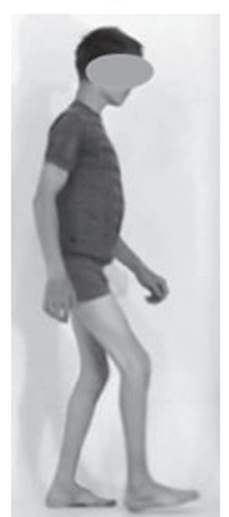

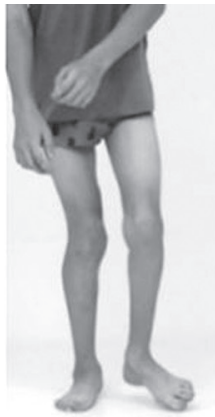

f

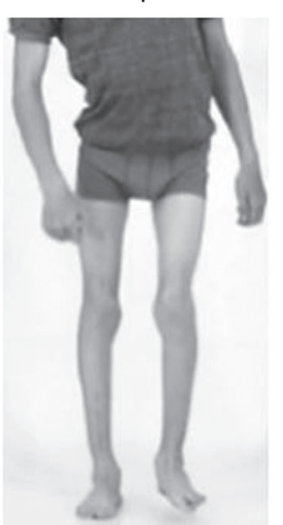

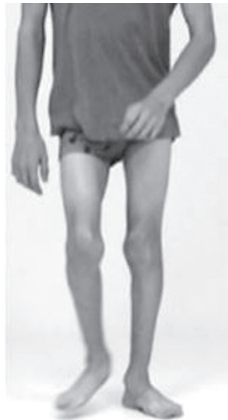

g

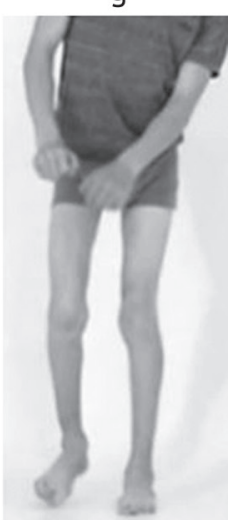

Fig. 2 Gait of patient C., 14 years old, GMFCS II, top row - before treatment, bottom row - 1.5 years after surgery: $a$ - initial contact (before treatment on the whole foot, on the heel after it); $b$ - mid stance (increased foot dorsiflexion before treatment, pathological, excessive flexion in the knee joint; normalization of the kinematic parameters of the maximum dorsal flexion of the foot after treatment and improvement of knee joint extension); $c$ - foot-off (toe-off), stride length did not increase after the operation; $d$ - mid swing, normalization of knee flexion, sufficient step clearance before and after the operation; $e$ - position of the knee joint before contact of the foot with the surface, improvement of knee joint flexion after surgery; $f$, $g$ - external deviation of the bearing limb foot and normal orientation of the bearing foot after treatment

Computer analysis of gait revealed the following changes in kinematic and kinetic parameters (Tables $4,5,6$ ).
The results presented in Table 4 show, first of all, a significant decrease in the angle of maximum dorsal flexion of 
the foot in the support phase of the gait (decrease, on average, by $39 \%$ for the first group and by $32 \%$ in the second). In addition, normalization of the foot orientation relative to the walking direction vector was achieved in both groups.

Surgical treatment reliably improved the indicators of movements in the knee joint, reducing the flexion angle at the initial moment of the support phase and, what is extremely important, in the mid stance almost a twofold decrease in the flexion angle was observed. In addition, the appearance of the moment of force of flexors also showed normalization of the work of the antagonist muscles of the knee joint which found themselves in biomechanically favorable conditions after surgical treatment.

In general, an improvement in the kinematics of movements in the knee and ankle joints, an improvement in the orientation of the foot relative to the vector of walking movement is clearly visible. There was a significant decrease in knee flexion at the time of initial contact in both groups. Moreover, the improvement in knee extension during the stance phase was accompanied by a decrease in effort and energy generation, which reflects a decrease in the energy consumption by walking. On the other hand, no significant changes in the kinetic parameters of foot movements were found when comparing the parameters in the preand postoperative period. However, the magnitude of the moment of the force of the plantar push and the power of plantar flexion in the group of the natural crouch gait pattern were higher than in the iatrogenic pathological gait.

Table 4

Changes in the kinematic and kinetic parameters of the ankle joint, duration of the support phase of the gait cycle

\begin{tabular}{|c|c|c|c|c|}
\hline \multirow{2}{*}{ Parameter } & \multicolumn{2}{|c|}{ Natural crouch gait pattern } & \multicolumn{2}{|c|}{ Iatrogenic crouch gait pattern } \\
\hline & Before operation & After operation & Before operation & After operation \\
\hline $\begin{array}{l}\text { Foot position at onset of the } \\
\text { stance ; }{ }^{\circ}\end{array}$ & $14.8 \pm 2.99$ & $3.50 \pm 0.36 \mathrm{P}=0.002$ & $12.7 \pm 6.03$ & $6.1 \pm 5.70 \mathrm{P}=0.008$ \\
\hline $\begin{array}{l}\text { Maximum foot dorsiflexion angle } \\
\text { in stance; }{ }^{\circ}\end{array}$ & $27.3 \pm 5.33$ & $\begin{array}{c}16.8 \pm 8.03 \text { positive } \\
\text { dynamics by } 39 \% \\
\mathrm{P}=0.015\end{array}$ & $26.5 \pm 10.3$ & $\begin{array}{c}18.2 \pm 10.33 \text { positive } \\
\text { dynamics by } 32 \% \\
P=0.003\end{array}$ \\
\hline $\begin{array}{l}\text { Foot position at the toe-off } \\
\text { moment; }{ }^{\circ}\end{array}$ & $-1.35 \pm 6.30$ & $-0.23 \pm 6.60$ & $-0.8 \pm 7.49$ & $-1.88 \pm 6.50$ \\
\hline Duration of the stride phase, $\%$ & $68.7 \pm 7.86$ & $65.9 \pm 5.72$ & $66.1 \pm 8.80$ & $68.6 \pm 7.67$ \\
\hline $\begin{array}{l}\text { Angle of foot orientation relative } \\
\text { walking vector; }{ }^{\circ}\end{array}$ & $-33.5 \pm 27.2$ & $-18.8 \pm 22.7$ & $-25.1 \pm 18.2$ & $-11.9 \pm 19.2$ \\
\hline $\begin{array}{l}\text { Force moment of plantar flexors; } \\
\mathrm{Nm} / \mathrm{kg}\end{array}$ & $0.95 \pm 0.26$ & $0.92 \pm 0.14$ & $0.88 \pm 0.37$ & $0.86 \pm 0.26$ \\
\hline Power of plantar push; W/kg & $1.27 \pm 0.72$ & $1.35 \pm 0.44$ & $1.21 \pm 0.57$ & $1.31 \pm 0.99$ \\
\hline
\end{tabular}

Table 5

Change in knee joint kinematic and kinetic parameters

\begin{tabular}{|l|c|c|c|c|}
\hline \multirow{2}{*}{ Parameter } & \multicolumn{2}{|c|}{ Natural crouch gait pattern } & \multicolumn{2}{c|}{ Iatrogenic crouch gait pattern } \\
\cline { 2 - 5 } & Before operation & After operation & Before operation & After operation \\
\hline $\begin{array}{l}\text { Knee flexion angle at onset of the } \\
\text { stance; }^{\circ}\end{array}$ & $45.7 \pm 3.92$ & $27.0 \pm 6.78 \mathrm{P}=0.004$ & $39.2 \pm 12.28$ & $\begin{array}{l}26.1 \pm 14.9 \\
\mathrm{P}=0.0008\end{array}$ \\
\hline $\begin{array}{l}\text { Angle of peak knee extension in } \\
\text { stance; }\end{array}$ & $38.4 \pm 11.38$ & $20.1 \pm 8.98 \mathrm{P}=0.004$ & $28.3 \pm 18.7$ & $\begin{array}{l}13.4 \pm 18.8 \\
\mathrm{P}=0.0002\end{array}$ \\
\hline $\begin{array}{l}\text { Angle of maximum flexion in } \\
\text { swing; }\end{array}$ & $66.0 \pm 14.7$ & $47.8 \pm 5.64$ & $56.5 \pm 13.5$ & $49.1 \pm 15.83$ \\
\hline $\begin{array}{l}\text { Moment of maximum flexion in } \\
\text { swing (\% gait cycle) }\end{array}$ & $81.3 \pm 6.25$ & $78.8 \pm 7.87$ & $82.9 \pm 4.96$ & $80.9 \pm 5.05$ \\
\hline Moment of extensors force; Nm/kg & $1.08 \pm 0.55$ & $0.77 \pm 0.22$ & $0.96 \pm 0.50$ & $0.61 \pm 0.42 \mathrm{P}=0.001$ \\
\hline Moment of force, flexors; Nm/kg & $0.03 \pm 0.08$ & $0.15 \pm 0.07 \mathrm{P}=0.004$ & $0.12 \pm 0.17$ & $0.36 \pm 0.28 \mathrm{P}=0.0005$ \\
\hline Extension capacity; W/kg & $0.65 \pm 0.43$ & $0.66 \pm 0.43$ & $0.68 \pm 0.42$ & $0.61 \pm 0.55$ \\
\hline
\end{tabular}

Table 6

Changes in kinematic and kinetic parameters of the hip joint, pelvis and GPS

\begin{tabular}{|c|c|c|c|c|}
\hline \multirow{2}{*}{ Parameter } & \multicolumn{2}{|c|}{ Natural crouch gait pattern } & \multicolumn{2}{|c|}{ Iatrogenic crouch gait pattern } \\
\hline & Before surgery & After surgery & Before surgery & After surgery \\
\hline GPS & $17.1 \pm 3.01$ & $13.4 \pm 3.19$ & $15.9 \pm 6.16$ & $14.8 \pm 4.6$ \\
\hline Femur position at initial contact; ${ }^{\circ}$ & $43.6 \pm 12.1$ & $37.1 \pm 4.45$ & $39.5 \pm 10.8$ & $41.1 \pm 14.7$ \\
\hline $\begin{array}{l}\text { Maximum angle of femur } \\
\text { extension in support phase ; }\end{array}$ & $14.6 \pm 12.8$ & $9.1 \pm 9.74$ & $10.0 \pm 10.1$ & $10.8 \pm 16.6$ \\
\hline $\begin{array}{l}\text { Rotation of the femur in support } \\
\text { phase; }^{\circ}\end{array}$ & $26.3 \pm 11.48$ & $14.1 \pm 18.2$ & $19.2 \pm 16.7$ & $17.3 \pm 14.87$ \\
\hline Pelvic tilt; ${ }^{\circ}$ & $14.4 \pm 9.53$ & $20.8 \pm 5.18$ & $17.8 \pm 10.6$ & $22.4 \pm 12.7$ \\
\hline
\end{tabular}




\section{DISCUSSION}

The work of Rodda et al. [8] presented a classification that has become generally accepted and is a starting point for deeper studies of pathological gait patterns in children and adolescents with spastic diplegia, based on the kinematics in the sagittal plane. The crouch gait pattern is defined as a symmetrical gait where the foot is in dorsiflexion throughout the stance phase of the gait cycle, there is excessive flexion in the knee and hip joints, and the pelvis may be in the normal position or tilted posteriorly. The crouch gait pattern is seen with other types of gait within the flexed knee gait, where the knee joint is flexed more than $15^{\circ}$ at the initial contact (it corresponds to more than 1 SD for a 6-year-old child), which may include jump gait, apparent patterns equinus and crouch gait [5, 9, 22]. However, the crouch gait pattern is defined with an excessive flexion position in the knee joint and dorsal flexion of the foot throughout the entire stance phase [5, 8].

The abnormalities found in the crouch gait are well documented and include spasticity/retraction of the knee and hip flexors, torsion deformities of the hip, external rotational foot position usually associated with severe planovalgus deformity, patella alta [8, 11, 36 ]. Such changes lead to the pathology of biomechanical levers and gradual displacement of the direction of the support reaction vector to a permanent position posterior to the axis of rotation in the knee joint, which aggravates the situation [11, 12, 20, 37]. That is, biomechanical disorders are found not only in the sagittal plane, but also in the horizontal and frontal planes [19].

This type of pathological gait pattern is usually observed in children over 12 years of age, is associated with the completion of growth, with an increase in body weight, puberty and is considered as the evolution of other types observed at an earlier age (equinus gait, jump gait) [8, 14, 21 ]. In addition, computerized gait analysis may detect abnormal activity of the quadriceps (m. rectus femoris) in the non-supporting phase of the gait cycle, characteristic of stiff knee gait [6, 8, 17, 38].

The development of weakness of the lower leg triceps and a decrease in the force of knee extension is considered critical in the development of the crouch gait pattern, since these two elements form an important interdependent biomechanical couple by walking to achieve extension of the knee joint and reduce the energy intensity of walking $[8,20,33,39,40] \ldots$

Moreover, in addition to the natural development of this gait pattern, the iatrogenic crouch gait pattern is detected after unjustified fibromyotomies and isolated lengthening of the Achilles tendon performed at an early age [22, 33]. The subsequent inevitable weakening of the lower leg triceps leads to a loss of function of the soleus muscle, contracting eccentrically, absorbing the kinetic energy of the bearing limb, and pathological flexion of the knee joint in the support phase [40-43]. As shown by Rose et al. [39], only aponeurotomy of the gastrocnemius muscles allows preserving the push force in plantar flexion of the foot and prevents the development of triceps weakness.

As a rule, the available publications consider the issues of population, orthopedic aspects, methods and results of correction of this type of pathological gait together, both for naturally developed crouch gait and for iatrogenic one, indicating that there is no reliable effect of age on the result of multilevel interventions in children [14, 31,36 , $44,45]$. However, our study revealed that in the group of iatrogenic gait disorders, the age of the surgical treatment was significantly lower than in the group with naturally developed gait pathology. At the same time, with the natural development of crouch gait, GMFCS level II disorders are more common, while GMFCS level III is characteristic for patients without previous surgical treatment.

At the moment, there is no need to prove the feasibility of performing multilevel simultaneous surgical interventions in the correction of orthopedic complications in cerebral palsy. This is also true for the crouch gait pattern [23, 30, 31, 46-48].

As our study showed, multilevel correction of orthopedic deformities and joint contractures in the crouch gait pattern improves the parameters of foot dorsiflexion and extension of the knee joint in the support phase of the gait cycle, rotational orientation of the knee joint and foot relative to the patient's motion vector. These main biomechanical disorders that cause not only persistence but also progression of this pathological type of gait were eliminated. As a result, the overall Gait Profile Score improved in both groups.

The literature does not report on the comparison of the surgical methods of correction depending on the natural or iatrogenic development of crouch gait [15, 30, 37, 48]. Our study showed that the elements of intervention are different for these two clinical situations: shortening of the Achilles tendon was required to correct excessive dorsal flexion of the foot in iatrogenic disorders, and, often, in combination with transfer of the peroneal longus muscle to the heel bone. We also note the need for correction of foot deformity simultaneously with an attempt to enhance active plantar flexion using various types of arthrodesis to eliminate the pathology of biomechanical levers in order to shift the support reaction vector anteriorly from the axis of rotation of the knee joint.

Today, the 3D gait analysis is an integral part of the diagnosis and planning of orthopedic surgery in patients with cerebral palsy, allowing the determination of pathological values and gait patterns in patients with cerebral palsy [7, 47].

Our research revealed the peculiarities of the iatrogenic crouch gait development as opposed to the natural one. An iatrogenic disorder develops due to a serious postoperative weakening of the triceps of the lower leg without significant rotational deviations of the foot from the vector of motion in the support phase of the gait cycle. At the same time, the pathological values of the motion range and angles in the joints in the sagittal plane are close in these two groups of patients. We should note the tendency towards a smaller flexion angle in the non-support phase in patients with iatrogenic pattern, which is an element of stiff knee gait. The strength indices of the plantar flexors were equally weakened in both groups; however, the push power, while remaining pathologically low, was higher in the iatrogenic group. The latter is due to a lesser severity of 
neurological disorders observed in our sample in patients with the iatrogenic crouch gait pattern

Thus, the negative effect of early interventions on plantar flexors (fibromyotomy according to the Ulzibat method, open lengthening of the Achilles tendon in children with spastic diplegia [32, 33, 43, 49]) is obvious and manifests itself in the early development of a pathological crouch gait pattern in children without torsional deformities (without disorders of biomechanical levers in the horizontal plane) and in children with initially high levels of motor activity and not prone to develop this complication.

Computer gait analysis showed that multilevel surgical interventions in both groups enable to improve the parameters of the knee flexion angle at initial contact, to increase the magnitude of knee joint extension in the support phase of the gait cycle, to normalize the orientation of the foot relative to the motion vector, to reduce or completely correct the pathological dorsal flexion of the foot in the support phase of the gait and reduce the energy consumption of movements in the support phase of the gait cycle. However, there was no significant increase in the parameters reflecting the strength characteristics of the plantar flexors, which apparently reflects the pronounced suppression of the function of this muscle group in the development of crouch gait. We emphasize once again that a pronounced decrease in the functional capabilities of the plantar flexors in natural crouch gait is a natural evolution of the situation characteristic of patients with GMFCS level III, less often with level II. While in iatrogenic crouch gait, the loss of leg triceps function is the result of staged or even single fibromyotomies or lengthening of the Achilles tendon performed at an early age in patients with a less severe level of impairment of global motor functions (GMFCS level I-II).

In any case, stabilization of foot position in the horizontal plane along with an improvement in the kinetic and kinematic parameters for the knee joint is sufficient to reduce the energy consumption in the support phase of the stride and, in general, to increase GPS even in a pronounced decrease in the function of the plantar flexors.

\section{CONCLUSION}

The crouch gait pattern is not homogeneous, both in terms of natural and iatrogenic development, and in terms of orthopedic disorders. The iatrogenic pattern develops with excessive surgical weakening of the plantar flexors of the foot, even in the absence of pathological rotation of the lower limb segments at an earlier age and in patients with a lower level of global motor disorders according to GMFCS. Planning of multilevel surgical treatment is based on 3D gait analysis and should be aimed at eliminating all, both primary and secondary, orthopedic components of the pathology that determine the crouch gait pattern. Surgical treatment improves kinetic and kinematic parameters in the knee joint and the kinematics of the ankle joint.

Publication ethics: patients gave voluntary informed consent to the publication.

Conflict of interest: not declared.

Funding source: not stated.

\section{REFERENCES}

1. Quinby J.M., Abraham A. Musculoskeletal problems in cerebral palsy. Current Paediatrics, 2005, vol. 15, no. 1, pp. 9-14.

2. Temelli Y., Akalan N.E. Diz fleksiyon kontraktüründe tedavi yaklaşimlari [Treatment approaches to flexion contractures of the knee]. Acta Orthop. Traumatol. Turc., 2009, vol. 43, no. 2, pp. 113-120. DOI: 10.3944/AOTT.2009.113. (in Turkish)

3. El-Sobky T.A., Fayyad T.A., Kotb A.M., Kaldas B. Bony reconstruction of hip in cerebral palsy children Gross Motor Function Classification System levels III to V: a systematic review. J. Pediatr. Orthop. B, 2018, vol. 27, no. 3, pp. 221-230. DOI: $10.1097 / B P B .0000000000000503$.

4. Galey S.A., Lerner Z.F., Bulea T.C., Zimbler S., Damiano D.L. Effectiveness of surgical and non-surgical management of crouch gait in cerebral palsy: A systematic review. Gait Posture, 2017, vol. 54, pp. 93-105. DOI: 10.1016/j. gaitpost.2017.02.024.

5. Haumont T., Church C., Hager S., Cornes M.J., Poljak D., Lennon N., Henley J., Taylor D., Niller T., Miller F. Flexedknee gait in children with cerebral palsy: a 10-year follow-up study. J. Child. Orthop., 2013, vol. 7, no. 5, pp. 435-443. DOI: $10.1007 / \mathrm{s} 11832-013-0505-8$.

6. Sutherland D.H., Davids J.R. Common gait abnormalities of the knee in cerebral palsy. Clin. Orthop. Relat. Res., 1993, no. 288. P. 139-147.

7. Wren T.A., Rethlefsen S., Kay R.M. Prevalence of specific gait abnormalities in children with cerebral palsy: influence of cerebral palsy subtype, age, and previous surgery. J. Pediatr. Orthop., 2005, vol. 25, no. 1, pp. 79-83. DOI: 10.1097/00004694-200501000-00018.

8. Rodda J.M., Graham H.K., Carson L., Galea M.P., Wolfe R. Sagittal gait patterns in spastic diplegia. J. Bone Joint Surg. Br., 2004, vol. 86, no. 2, pp. 251-258. DOI: 10.1302/0301-620x.86b2.13878.

9. Kedem P., Scher D.M. Evaluation and management of crouch gait. Curr. Opin. Pediatr., 2016, vol. 28, no. 1, pp. 55-59. DOI: 10.1097/MOP.0000000000000316.

10.Vuillermin C., Rodda J., Rutz E., Shore B.J., Smith K., Graham H.K. Severe crouch gait in spastic diplegia can be prevented: a population-based study. J. Bone Joint Surg. Br., 2011, vol. 93, no. 12, pp. 1670-1675. DOI: 10.1302/0301620X.93B12.27332.

11. Arnold A.S., Anderson F.C., Pandy M.G., Delp S.L. Muscular contributions to hip and knee extension during the single limb stance phase of normal gait: a framework for investigating the causes of crouch gait. J. Biomech., 2005, vol. 38, no. 11, pp. 2181-2189. DOI: 10.1016/j.jbiomech.2004.09.036. 
12.Hicks J.L., Schwartz M.H., Arnold A.S., Delp S.L. Crouched postures reduce the capacity of muscles to extend the hip and knee during the single-limb stance phase of gait. J. Biomech., 2008, vol. 41, no. 5, pp. 960-967. DOI: 10.1016/j. jbiomech.2008.01.002.

13. Sutherland D.H., Olshen R., Cooper L., Woo S.L. The development of mature gait. J. Bone Joint Surg. Am., 1980, vol. 62, no. 3, pp. 336-353.

14. Bell K.J., Ounpuu S., DeLuca P.A., Romness M.J. Natural progression of gait in children with cerebral palsy. J. Pediatr. Orthop., 2002, vol. 22, no. 5, pp. 677-682.

15. Rodda J.M., Graham H.K., Nattrass G.R., Galea M.P., Baker R., Wolfe R. Correction of severe crouch gait in patients with spastic diplegia with use of multilevel orthopaedic surgery. J. Bone Joint Surg. Am., 2006, vol. 88, no. 12, pp. 26532664. DOI: 10.2106/JBJS.E.00993.

16. Rose G.E., Lightbody K.A., Ferguson R.G., Walsh J.C., Robb J.E. Natural history of flexed knee gait in diplegic cerebral palsy evaluated by gait analysis in children who have not had surgery. Gait Posture, 2010, vol. 31, no. 3, pp. 351-354. DOI: 10.1016/j.gaitpost.2009.12.006.

17. Sutherland D.H., Cooper L. The pathomechanics of progressive crouch gait in spastic diplegia. Orthop. Clin. North Am., 1978, vol. 9, no. 1, pp. 143-154.

18. Murphy K.P. Cerebral palsy lifetime care - four musculoskeletal conditions. Dev. Med. Child. Neurol., 2009, vol. 51, no. Suppl. 4, pp. 30-37. DOI: 10.1111/j.1469-8749.2009.03431.x.

19. Theologis T. Lever arm dysfunction in cerebral palsy gait. J. Child. Orthop., 2013, vol. 7, no. 5, pp. 379-382. DOI: 10.1007/ s11832-013-0510-y.

20. Miller F. Cerebral palsy. New York, Springer. 2005.

21.Opheim A., Jahnsen R., Olsson E., Stanghelle J.K. Balance in relation to walking deterioration in adults with spastic bilateral cerebral palsy. Phys. Ther., 2012, vol. 92, no. 2, pp. 279-288. DOI: 10.2522/ptj.20100432.

22.Amen J., ElGebeily M., El-Mikkawy D.M.E., Yousry A.H., El-Sobky T.A. Single-event multilevel surgery for crouching cerebral palsy children: Correlations with quality of life and functional mobility. J. Musculoskelet. Surg. Res., 2018, vol. 2 , no. 4 , pp. 148-155.

23.Lamberts R.P., Burger M., du Toit J., Langerak N.G. A Systematic Review of the Effects of Single-Event Multilevel Surgery on Gait Parameters in Children with Spastic Cerebral Palsy. PLoS One, 2016, vol. 11, no. 10, pp. e0164686. DOI:10.1371/journal. pone.0164686.

24. Popkov D.A., Zmanovskaya V.A., Gubina E.B., Leonchuk S.S., Butorina M.N., Pavlova O.L. Rezultaty mnogourovnevykh odnomomentnykh ortopedicheskikh operatsii i rannei reabilitatsii $\mathrm{v}$ komplekse $\mathrm{s}$ botulinoterapiei $\mathrm{u}$ patsientov so spasticheskimi formami tserebralnogo paralicha [The results of single-event multilevel orthopedic surgeries and the early rehabilitation used in complex with botulinum toxin treatment in patients with spastic forms of cerebral palsy]. Zh. Nevrol. Psikhiatr. im. S.S. Korsakova, 2015, vol. 115, no. 4, pp. 41-48. (in Russian) DOI: 10.17116/jnevro20151154141-48.

25.Gatamov O.I., Chibirov G.M., Borzunov D.Y., Popkov D.A. Khirurgicheskoe ortopedicheskoe lechenie vzroslykh patsientov s dtsp: obzor literatury i predvaritelnyi analiz sobstvennykh rezultatov [Surgical orthopedic treatment of adult patients with cerebral palsy: review of the literature and preliminary analysis of the own results]. Genij Ortopedii, 2018, vol. 24, no. 4, pp. 538-547. (in Russian) DOI: 10.18019/1028-4427-2018-24-4-538-54.

26. Rang M., Silver R., De la Garza J. Cerebral palsy. In: Lovell W.W., Winter R.B., eds. Pediatric Orthopaedics. $2^{\text {nd }}$ Ed. Philadelphia, JB Lippincott Co, 1986, vol. 1, pp. 345-396.

27. Van den Hecke A., Malghem C., Renders A., Detrembleur C., Palumbo S., Lejeune T.M. Mechanical work, energetic cost, and gait efficiency in children with cerebral palsy. J. Pediatr. Orthop., 2007, vol. 27, no. 6, pp. 643-647. DOI: 10.1097/ BPO.0b013e318093f4c3.

28. Graham H.K., Baker R., Dobson F., Morris M.E. Multilevel orthopaedic surgery in group IV spastic hemiplegia. J. Bone Joint Surg. Br., 2005, vol. 87, no. 4, pp. 548-555. DOI: 10.1302/0301-620X.87B4.15525.

29. Chibirov G.M., Dolganova T.I., Dolganov D.V., Popkov D.A. Analiz prichin patologicheskikh patternov kinematicheskogo lokomotornogo profilia po dannym kompiuternogo analiza pokhodki u detei so spasticheskimi formami DTsP [Analysis of the causes of pathological patterns of the kinematic locomotor profile according to the data of gait computer analysis in children with spastic forms of cerebral palsy]. Genij Ortopedii, 2019, vol. 25, no. 4, pp. 493-500. (in Russian) DOI: 10.18019/1028-4427-2019-25-4-493-500.

30. Aroojis A., Patel M., Shah A., Sarathy K., Vaidya S., Mehta R. Distal femoral extension osteotomy with $90^{\circ}$ pediatric condylar locking compression plate and patellar tendon advancement for the correction of crouch gait in cerebral palsy. Indian J. Orthop., 2019, vol. 53, no. 1, pp. 45-52. DOI: 10.4103/ortho.IJOrtho_410_17.

31.Dreher T., Thomason P., Švehlík M., Döderlein L., Wolf S.I., Putz C., Uehlein O., Chia K., Steinwender G., Sangeux M., Graham H.K. Long-term development of gait after multilevel surgery in children with cerebral palsy: a multicentre cohort study. Dev. Med. Child. Neurol., 2018, vol. 60, no. 1, pp. 88-93. DOI: 10.1111/dmcn.13618.

32. Gómez-Andrés D., Pulido-Valdeolivas I., Martín-Gonzalo J.A., López-López J., Martinez-Caballero I., Gómez-Barrena E., Rausell E. Evaluación externa de los cambios funcionales y la marcha tras una sesión de miofibrotomía múltiple en escolares con diplejía espástica [External evaluation of gait and functional changes after a single-session multiple myofibrotenotomy in school-aged children with spastic diplegia]. Rev. Neurol., 2014, vol. 58, no. 6, pp. 247-254. (in Spanish)

33. Pilloni G., Pau M., Costici F., Condoluci C., Galli M. Use of 3D gait analysis as predictor of Achilles tendon lengthening surgery outcomes in children with cerebral palsy. Eur. J. Phys. Rehabil. Med., 2019, vol. 55, no. 2, pp. $250-257$. DOI: 10.23736/S1973-9087.18.05326-1.

34. Read H.S., Hazlewood M.E., Hillman S.J., Prescott R.J., Robb J.E. Edinburgh visual gait score for use in cerebral palsy. J. Pediatr. Orthop., 2003, vol. 23, no. 3, pp. 296-301.

35.Leardini A., Sawacha Z., Paolini G., Ingrosso S., Nativo R., Benedetti M.G. A new anatomically based protocol for gait analysis in children. Gait Posture, 2007, vol. 26, no. 4, pp. 560-571. DOI: 10.1016/j.gaitpost.2006.12.018. 
36. Svehlik M., Steinwender G., Kraus T., Saraph V., Lehmann T., Linhart W.E., Zwick E.B. The influence of age at singleevent multilevel surgery on outcome in children with cerebral palsy who walk with flexed knee gait. Dev. Med. Child. Neurol., 2011, vol. 53, no. 8, pp. 730-735. DOI: 10.1111/j.1469-8749.2011.03995.x.

37. Arnold A.S., Liu M.Q., Schwartz M.H., Ounpuu S., Dias L.S., Delp S.L. Do the hamstrings operate at increased muscletendon lengths and velocities after surgical lengthening? J. Biomech., 2006, vol. 39, no. 8, pp. 1498-1506. DOI: 10.1016/j. jbiomech.2005.03.026.

38. Wren T.A., Gorton G.E. 3rd, Ounpuu S., Tucker C.A. Efficacy of clinical gait analysis: A systematic review. Gait Posture, 2011, vol. 34, no. 2, pp. 149-153. DOI: 10.1016/j.gaitpost.2011.03.027.

39. Rose S.A., DeLuca P.A., Davis R.B. 3rd, Ounpuu S., Gage J.R. Kine $\neg$ matic and kinetic evaluation of the ankle after lengthening of the gastroc $\neg$ nemius fascia in children with cerebral palsy. J. Pediatr. Orthop., 1993, vol. 13, no. 3, pp. 727732. DOI: $10.1097 / 01241398-199311000-00007$.

40. Shore B.J., White N., Graham H.K. Surgical correction of equinus deformity in children with cerebral palsy: a systematic review. J. Child. Orthop., 2010, vol. 4, no. 4, pp. 277-290. DOI: 10.1007/s11832-010-0268-4.

41. Borton D.C., Walker K., Pirpiris M., Nattrass G.R., Graham H.K. Iso $\neg$ lated calf lengthening in cerebral palsy. Outcome analysis of risk factors. J. Bone Joint Surg. Br., 2001, vol. 83, no. 3, pp. 364-370. DOI: 10.1302/0301-620x.83b3.10827.

42. Dietz F.R., Albright J.C., Dolan L. Medium-term follow-up of Achilles tendon lengthening in the treatment of ankle equinus in cerebral palsy. Iowa Orthop. J., 2006, vol. 26, pp. 27-32.

43. Segal L.S., Thomas S.E., Mazur J.M., Mauterer M. Calcaneal gait in spastic diplegia after heel cord lengthening: a study with gait analysis. J. Pediatr. Orthop., 1989, vol. 9, no. 6, pp. 697-701. DOI: 10.1097/01241398-198911000-00013.

44.McGinley J.L., Dobson F., Ganeshalingam R., Shore B.J., Rutz E., Graham H.K. Single-event multilevel surgery for children with cerebral palsy: a systematic review. Dev. Med. Child. Neurol., 2012, vol. 54, no. 2, pp. 117-128. DOI: 10.1111/j.1469-8749.2011.04143.x.

45.Wilson N.C., Chong J., Mackey A.H., Stott N.S. Reported outcomes of lower limb orthopaedic surgery in children and adolescents with cerebral palsy: a mapping review. Dev. Med. Child. Neurol., 2014, vol. 56, no. 9, pp. 808-814. DOI: $10.1111 /$ dmcn.12431.

46. Chang F.M., Rhodes J.T., Flynn K.M., Carollo J.J. The role of gait analysis in treating gait abnormalities in cerebral palsy. Orthop. Clin. North Am., 2010, vol. 41, no. 4, pp. 489-506. DOI: 10.1016/j.ocl.2010.06.009.

47.Ławniczak D., Jóźwiak M., Manikowska F. Ocena całkowitej predkości liniowej i katowej stawu kolanowego u chorych z postacia spastyczna mózgowego porazenia po operacyjnym leczeniu tzw. "deformacji dźwigniowozaleznych" kończyn dolnych--badanie prospektywne [Assessment of absolute knee joint linear and angular velocity in patients with spastic cerebral palsy after operative treatment of lever arm disfunction deformities--prospective study]. Chir. Narzadow Ruchu Ortop. Pol., 2010, vol. 75, no. 2, pp. 92-97. (in Polish)

48. Novacheck T.F., Stout J.L., Gage J.R., Schwartz M.H. Distal femoral extension osteotomy and patellar tendon advancement to treat persistent crouch gait in cerebral palsy. Surgical technique. J. Bone Joint Surg. Am., 2009, vol. 91, no. Suppl. 2, pp. 271-286. DOI: 10.2106/JBJS.I.00316.

49. Shishov S.V., Ivshin V.G. Minimalno invazivnye operatsii na myshtsakh u detei s DTsP. Opyt piatiletnego primeneniia [Minimally invasive muscle surgeries in children with cerebral palsy. Five-years experience]. Vestnik Novykh Meditsinskikh Tekhnologii (Elektronnoe izdanie), 2016, no. 2, pp. 137-141. (in Russian)

Received: 04.02.2020

\section{Information about the authors:}

1. Tamara I. Dolganova, M.D., Ph.D., Ilizarov National Medical Research Centre for Traumatology and Orthopedics, Kurgan, Russian Federation, Email: rjik532007@rambler.ru

2. Orhan I. Gatamov, M.D., Ilizarov National Medical Research Centre for Traumatology and Orthopedics, Kurgan, Russian Federation

3. Georgy M. Chibirov, M.D., Ph.D., Ilizarov National Medical Research Centre for Traumatology and Orthopedics, Kurgan, Russian Federation, Email: georgii_chibirov@mail.ru

4.Dmitrii V. Dolganov, Ph.D. of Biological Sciences, Ilizarov National Medical Research Centre for Traumatology and Orthopedics, Kurgan, Russian Federation, Email: Paradigma-DV@rambler.ru

5.Dmitry A. Popkov, M.D., Ph.D., Professor of RAS, correspondent member French Academy of Medical Sciences, Ilizarov National Medical Research Centre for Traumatology and Orthopedics, Kurgan, Russian Federation, Email: dpopkov@mail.ru 